\title{
Identification of food-derived peptides in human blood after ingestion of corn and wheat gluten hydrolysates
}

\author{
Akika Ejima $^{\mathrm{a}}$, Megumi Nakamura ${ }^{\mathrm{b}}$, Yasushi A. Suzuki ${ }^{\mathrm{b}}$ and Kenji Sato ${ }^{\mathrm{a}^{*}}$ \\ aDivision of Applied Biosciences, Graduate School of Agriculture, Kyoto University, Kitashirakawaoiwake-cho, Sakyo-ku, Kyoto 606- \\ 8502, Japan

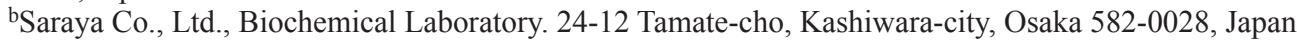 \\ *Corresponding author: Kenji Sato, Division of Applied Biosciences, Graduate School of Agriculture, Kyoto University, Kitashirakawao- \\ iwake-cho, Sakyo-ku, Kyoto 606-8502, Japan. Tel: +81 75753 6444; Fax: +81 753 6400; E-mail: kensato@kais.kyoto-u.ac.jp \\ DOI: $10.31665 / J F B .2018 .2145$ \\ Received: March 02, 2018; Revised received \& accepted: May 20, 2018 \\ Citation: Ejima, A., Nakamura, M., Suzuki, Y.A., and Sato, K. (2018). Identification of food-derived peptides in human blood after inges- \\ tion of corn and wheat gluten hydrolysates. J. Food Bioact. 2: 104-111.
}

\begin{abstract}
Bioactive peptides in the body after ingestion of plant protein hydrolysates have been speculated but not identified. We aimed to establish an approach to identify small amounts of food-derived peptides in humans after ingestion of non-extracellular matrix protein hydrolysates. Corn and wheat gluten hydrolysates were digested using pancreatin and leucine aminopeptidase; the resultant peptides were identified via size-exclusion chromatography and reverse-phase HPLC-tandem mass spectrometry (MS/MS). Structures of indigestible peptides were confirmed via LC-MS/MS in multi-reaction monitoring mode. All indigestible peptides in the exopeptidase digest were diprolyl and di- and tripyroglutamyl peptides. Blood collected from healthy volunteers $(n=4)$ before and after ingestion of $9 \mathrm{~g}$ of the hydrolysates was assessed for the indigestible peptides via LC-MS/MS. Six peptides (Pro-Ala, Pro-Gly, Pro-Gln, pyroGlu-Pro, pyroGlu-Leu-Pro, and pyroGlu-Gln-Pro) significantly increased in human plasma up to $10-100 \mathrm{nM}$ compared to the baseline. This may hence be a powerful tool for identifying foodderived peptides in blood.
\end{abstract}

Keywords: Bioactive peptide; Protein hydrolysate; Blood; Liquid chromatography tandem mass-spectrometry; Food; Pyroglutamyl peptide.

\section{Introduction}

Enzymatic hydrolysates of food proteins, such as soy, corn, wheat, milk, and meat proteins, exert beneficial effects on health beyond those of conventional amino acid sources (Möller et al., 2008; Malaguti et al., 2014). In most cases, thermostable bacterial proteases having high endoproteinase activity but low exopeptidase activity are used to obtain hydrolysates of food proteins. Peptides in the endoproteinase digest are degraded by exopeptideases in digestive tract and resultant amino acids and di- and tripeptides penetrate enterocytes via amino acids transporters as well as peptide transporter 1 (PepT1) (Adibi, 1997; Miner-Williams et al., 2014). Some longer peptides can penetrate enterocytes via paracellular diffusion (Shimizu et al., 1997). Most di- and tripeptides are further degraded to amino acids by cytosolic and blood exopeptidases
(Hübl et al., 1989; Satake et al., 2002; Miner-Williams et al, 2014). Therefore, the majority of food-derived peptides were thought to be degraded into amino acids during digestion and absorption.

This concept was, however, dramatically altered owing to the detection of approximately 10-30 $\mu \mathrm{M}$ hydroxyproline (Hyp)-containing peptides in human plasma 1 hour after ingestion of $10 \mathrm{~g}$ of a collagen hydrolysate (Iwai et al., 2005). To isolate food-derived collagen peptides in human plasma, a series of size-exclusion chromatography (SEC) and reverse-phase (RP)-HPLC have previously been performed (Iwai et al., 2005; Ohara et al. 2007). To improve the resolution and detection of hydrophilic food-derived peptides in human plasma, pre-column derivatization with phenyl isothiocyanate (PITC) has been performed previously (Aito-Inoue et al., 2006; Shigemura et al., 2011; 2017). By comparing chromatograms before and after ingestion of collagen hydrolysates, seven 
Hyp-containing peptides; Pro-Hyp, Pro-Hyp-Gly, Ile-Hyp, LeuHyp, Hyp-Gly, Glu-Hyp, Ala-Hyp, and Pro-Gly have been identified (Shigemura et al., 2017). In most cases, Pro-Hyp accounts for more than $50 \%$ of total collagen peptides in human plasma. Pro-Hyp enhances fibroblast growth on a collagen gel (Shigemura et al., 2009; 2011) and production of glycosaminoglycans by fibroblasts and chondrocytes (Nakatani et al., 2009; Ohara et al., 2010), which partly explain the beneficial effects of collagen hydrolysates; improvement of wound healing (Sugihara et al., 2015) and skin (Proksch et al., 2014a,b) and joint conditions (Zdzieblik et al., 2017). However, collagen hydrolysates ingested comprised collagen peptides with an average molecular weight of $5000 \mathrm{Da}$ and did not contain Pro-Hyp (Iwai et al., 2005). These findings indicate that biological activities of peptides in the body rather than in food are well associated with the biological response on ingestion of protein hydrolysates.

Furthermore, ingestion of corn and wheat gluten hyrolysates also exerts beneficial effects on alcohol-induced liver damage and muscle injury after extensive physical exercise (Koikawa et al., 2009; Wu et al., 2014). To identify food-derived peptides after ingestion of corn and wheat gluten hydrolysates, the aforementioned technique was applied in our preliminary experiments. However, it was difficult to directly detect plant protein-derived peptides owing to their lower levels than those of extracellular proteinsderived peptides in blood. The objective of the present study was to establish an approach to identify small amounts of food-derived peptides in human blood after ingestion of non-extracellular matrix proteins to understand molecular mechanism for beneficial effects of protein hydrolysates on ingestion, which has so far been a black box.

\section{Materials and methods}

\subsection{Corn and wheat gluten hydrolysates}

Food-grade enzymatic hydrolysates of corn and wheat gluten were provided by Japan Food Peptide Institute (Osaka, Japan). These products were prepared by the method described in Japanese Patent No. 6190999. The corn and wheat gluten were digested by Alcalase and Neutrase (Novozymes, Bagsværd, Denmark). Contents of peptides with molecular weight of $1000 \mathrm{Da}$ or less in the corn gluten and wheat gluten hydrolysates were approximately 90 and $85 \%$, respectively (information from supplier).

\subsection{Regents}

Acetonitrile (HPLC-grade), methanol, formic acid, ammonium acetate, tris(hydroxymethyl)aminomethane (Tris), and porcine pancreatin with carboxypeptidase A activity were purchased from Nacalai Tesque (Kyoto, Japan). Porcine leucine aminopeptidase was purchased from Sigma-Aldrich (St. Louis, MO, USA). Piperidine, 4-methylmorpholine, $N, N$-dimethylformamide, $t$-butyl methyl ether, trifluoroacetic acid, $6 \mathrm{~mol} / \mathrm{L}$ hydrochloric acid, a standard mixture of amino acid (Type $\mathrm{H}$ ), and phenyl isothiocyanate (PITC) were purchased from Wako Chemical (Osaka, Japan). L-pyroglutamic acid, 9-fluorenylmethoxycarbonyl (Fmoc) amino acid derivatives, Fmoc amino acid-bound $p$-alkoxybenzyl alcohol (Alko) resin, proline-bound 2-chlorotrityl chloride (Barlos) resin, 1H-benzotriazol-1-yloxy-tri(pyrrolidino)phosphonium hexafluorophosphate (PyBOP), and 1-hydroxybenzotriazole (HOBt) were purchased from Watanabe Chemical Industries (Hiroshima,
Japan).

\subsection{Human study}

This study was approved by the ethical committee in Saraya and performed in accordance with the tenets of the Declaration of Helsinki under the supervision of medical doctors. Volunteers were informed of the study objectives and the risks of sample ingestion and blood collection. Healthy volunteers ( 2 male and 2 female, 20-40 years of age) ingested $180 \mathrm{~g}$ of jelly beverage containing $9 \mathrm{~g}$ of corn gluten hydrolysate or wheat gluten hydrolysate after a 12-h fast. Approximately $2 \mathrm{~mL}$ of venous blood was collected from the cubital vein before and after ingestion $(0.5,1,2$, and $4 \mathrm{~h})$. The plasma obtained from the venous blood was deproteinized by addition of an equal volume of ethanol. The ethanol-soluble fraction was harvested by centrifugation at $13,000 \mathrm{~g}$ for $10 \mathrm{~min}$ at $5{ }^{\circ} \mathrm{C}$ and stored at $-80^{\circ} \mathrm{C}$ until use.

\subsection{In vitro exopeptidase digestion of peptides in protein hydro- lysates}

Corn and wheat gluten hydrolysates were dissolved in $1 \mathrm{~mL}$ of $50 \mathrm{mM}$ Tris- $\mathrm{HCl}(\mathrm{pH} 8.0)$ to a final concentration of $0.25 \% \mathrm{w} / \mathrm{v}$. Pancreatin $(100 \mu \mathrm{g} / 3 \mu \mathrm{L}$ of the Tris- $\mathrm{HCl}$ buffer) and $2.45 \mathrm{U}$ of leucine aminopeptidase were added to the solution and digestion was carried out at $37^{\circ} \mathrm{C}$ for $24 \mathrm{~h}$. Enzymes were extracted via ultrafiltration using an Amicon Ultra 10K device (Merck Millipore, Burlington, MA, USA). The effluent was collected and used as the exopeptidase digest. To separate pyroglutamyl peptides from normal peptides, solid-phase extraction with a strong cation exchanger (AG50W- $\times 8$, hydrogen form, 100-200 mesh, Bio-Rad Laboratories, Hercules, CA, USA) was performed as described previously (Higaki-Sato et al., 2006; Kiyono et al., 2013). The resin was thoroughly washed with $50 \%$ methanol and packed into a spin column $(15 \mathrm{~mm} \times 7 \mathrm{~mm}$ i.d., $5.0 \mu \mathrm{m}$ pore size, UltrafreeMC, Merck Millipore). Two hundreds microlitters of $0.1 \%$ formic acid containing $10 \%$ acetonitrile were added onto the column and eluted by centrifugation at $815 \mathrm{~g}$ for equilibration (three times). Two hundreds microliters of the exopeptidase digest were loaded onto the column and eluted by centrifugation. The effluent was used as the pyroglutamyl peptide fraction.

\subsection{Identification of indigestible peptides in hydrolysate}

Peptides in the exopeptidase digest were fractionated via sizeexclusion chromatography (SEC) using Superdex Peptide 10/300 GL (GE Healthcare, Buckinghamshire, UK) and equilibrated with $0.1 \%$ formic acid containing $10 \%$ acetonitrile at a flow rate of 0.5 $\mathrm{mL} / \mathrm{min}$. Fractions were collected every $1 \mathrm{~min}$. Each fraction was dried under vacuum and peptides in each fraction were derivatized with 6-aminoquinolyl- $N$-hydroxysuccinimidyl carbamate (AccQ) (Toronto Research Chemicals, Toronto, ON, Canada). Structures of AccQ and derivatives are shown in Figure 1. The residue was dissolved in $20 \mu \mathrm{L}$ of $20 \mathrm{mM} \mathrm{HCl}$ and reacted with $20 \mu \mathrm{L}$ of $0.3 \%$ AccQ-acetonitrile solution and $60 \mu \mathrm{L}$ of $50 \mathrm{mM}$ sodium borate buffer ( $\mathrm{pH} 8.8$ ). The reaction was carried out at $50{ }^{\circ} \mathrm{C}$ for $10 \mathrm{~min}$ and terminated by cooling to $5{ }^{\circ} \mathrm{C}$. The reactant was mixed with $50 \mu \mathrm{L}$ of $5 \mathrm{mM}$ sodium phosphate buffer ( $\mathrm{pH} 7.5$ ) and clarified via passing through Cosmonice (R) filter (4 mm i.d., $0.45 \mu \mathrm{m}$, Nacalai Tesque). The filtrate $(20 \mu \mathrm{L})$ was injected to liquid chromatography-electrospray ionization-tandem mass spectrometer (LC-MS/ 


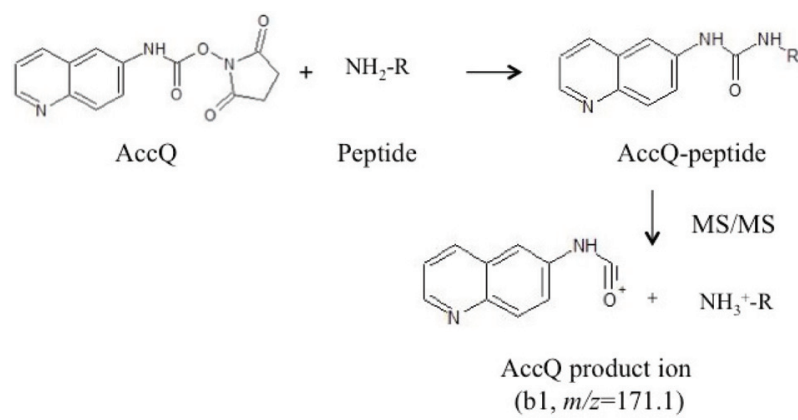

Figure 1. Derivatization of peptides with AccQ and generation of AccQderived product ions $(b 1, m / z=171.1)$ via tandem mass spectrometry.

MS, LCMS 8040, Shimadzu, Kyoto, Japan) equipped with an Inertsil ODS-3 column $(2 \mathrm{~mm}$ i.d. $\times 250 \mathrm{~mm}$, GL Science, Tokyo, Japan). A binary liner gradient was used with $0.1 \%$ formic acid (solvent $\mathrm{A}$ ) and $0.1 \%$ formic acid containing $80 \%$ acetonitrile (solvent B) at a flow rate of $0.2 \mathrm{~mL} / \mathrm{min}$. The gradient program was as follows: $0-15 \mathrm{~min}, 0-50 \% \mathrm{~B} ; 15-20 \mathrm{~min}, 50-100 \% \mathrm{~B}$; 20-25 min, $100 \%$ B; $25-25.1 \mathrm{~min}, 100-0 \% \mathrm{~B} ; 25.1-35 \mathrm{~min}, 0 \%$ B. The column was maintained at $40{ }^{\circ} \mathrm{C}$. AccQ-derivatives were specifically detected by selecting precursor ions, which generated ions of the AccQ-derived product (Figure 1; b1 ion, $m / z=171.1$ ) at positive mode (collision energy $-35 \mathrm{~V}$ ) in the range of $\mathrm{m} / \mathrm{z}=$ 250-350, 350-450, 450-550, and 550-650 (precursor ion scan). The pyroglutamyl peptide fraction $(200 \mu \mathrm{L})$ was subjected to SEC. An aliquot of the SEC fraction $(30 \mu \mathrm{L})$ was subjected to LC-MS with the aforementioned elution conditions. Total ion intensity was monitored at a positive mode in the range of $m / z=180-700$ (total ion scan). The $m / z$ of AccQ-peptides and pyroglutamyl peptides were recorded and entered into the program (LabSolutionsLCMS Ver. 5.5, Shimadzu) for product scan mode (collision energy -15 and $-35 \mathrm{~V}$ ) to estimate peptide structure.

\subsection{Peptide synthesis}

Peptides were synthesized per Fmoc strategy using a PSSM-8 peptide synthesizer (Shimadzu). Synthetic peptides were purified via RP-HPLC using a Cosmosil 5C 18 -MS-II column (10 mm i.d. $\times 250$ $\mathrm{mm}$, Nacalai Tesque). A binary liner gradient was used with $0.1 \%$ formic acid (solvent $\mathrm{A}$ ) and $0.1 \%$ formic acid containing $80 \%$ acetonitrile (solvent B) at a flow rate of $2 \mathrm{~mL} / \mathrm{min}$. The gradient program was as follows: $0-20 \mathrm{~min}, 0-50 \% \mathrm{~B} ; 20-30 \mathrm{~min}, 50-100 \%$ B; 30-35 min, $100 \%$ B; 35-35.1 min, 100-0\% B; 35.1-45 min, $0 \% \mathrm{~B}$. The column was maintained at $40{ }^{\circ} \mathrm{C}$. Elution of peptides was monitored spectrophotometrically at 214 and $254 \mathrm{~nm}$. Peptide purity of the peptides was confirmed via LC-MS. Contents of the peptides were evaluated via amino acid analysis of $\mathrm{HCl}$ hydrolysates (Bidlingmeyer et al., 1984; Sato et al., 1992).

\subsection{Peptide determination}

Five microlitters of the exopeptidase digest and a $100 \mu \mathrm{L}$ of the ethanol-soluble fraction of human plasma were dried under vacuum and then derivatized with AccQ as described above. Contents of the AccQ-peptides and pyroglutamyl peptides in the reaction mixture were determined via LC-MS/MS in multiple-reaction monitoring (MRM) mode. The elution condition was the same as that described above. The synthetic peptides were used for optimi- zation of the MRM condition using LabSolutionsLCMS Ver. 5.5 (Shimadzu).

\subsection{Statistical analysis}

The statistical analysis was performed using software GraphPad PRISM version 6.04 (USACO Corporation, Tokyo, Japan). Difference between the plasma peptide content before and after ingestion of the hydrolysates was analyzed using one-way analysis of variance (ANOVA) followed by Dunnett's multiple comparisons test for post-hoc analysis. A P-value less than 0.05 was considered as statically significant.

\section{Results}

\subsection{Identification of exopeptidase-resistant peptides}

The LC-MS/MS chromatograms of AccQ-derivatives in the SEC fractions in precursor ion scan mode at the scanning range of $\mathrm{m} / \mathrm{z}$ $=250-300$ and 350-450 are shown in Figure 2a and b, respectively; LC-MS chromatograms in the SEC fractions of pyroglutamyl peptide fraction, Figure $2 \mathrm{c}$. The $\mathrm{m} / \mathrm{z}$ of the peaks marked with uppercase or lowercase and asterisks were recorded. The peaks marked with uppercase were identified as amino acids designated with one-letter abbreviations on the basis of their retention times and $\mathrm{m} / \mathrm{z}$. The $\mathrm{m} / \mathrm{z}$ of the peaks marked with asterisks could not be assigned to peptides with any combination of amino acids. Compounds in the peaks marked with lowercase were subjected to MS/MS analysis. Product ion patterns are shown in the supplementary data. Table 1 summarizes the estimated structure of peptides based on $\mathrm{m} / \mathrm{z}$ of precursor and product ions. All estimated peptides were synthesized. In addition, all dipeptides with reversed sequence except for pyroglutamyl peptides were synthesized and could be resolved via RP-HPLC. Presence of the 26 and 28 indigestible peptides including those with reversed sequence (Pro-Ala, Pro-Ser, Pro-Val, Pro-Leu, Pro-Phe, and ProIle from the corn hydrolysate and Pro-Ser, Pro-Gln, Pro-Val, Pro-Gly, Pro-Phe, and Pro-Leu, Pro-Ile from the wheat gluten hydrolysate) were confirmed in the exopeptidase digests of corn and wheat gluten hydrolysates on the basis of retention time and MRM detection. All indigestible peptides from the hydrolysates were diprolyl and di- and tripyroglutamyl peptides. The contents of the indigestible peptides in the exopeptidase digests are shown in Figure 3. PyroGlu-Pro, pyroGlu-Gln, pyroGlu-Leu-Pro, and pyroGlu-Gln-Pro were the primary constituents in both digests. For prolyl dipeptides, the peptides with $\mathrm{C}$-terminal prolyl residues were directly detected via the precursor ion scan targeting product ions from AccQ, while those with N-terminal prolyl residues were not (Figure 2). However, MRM using the peptides with reversed sequence as standards detected dipeptides with $\mathrm{N}$-terminal prolyl residues (Figure 3). The sum of all indigestible peptides per corn and wheat gluten hydrolysates was 5.4 and $10.4 \%(\mathrm{w} / \mathrm{w})$, respectively. Therefore, approximately $90 \%$ of peptides were degraded into amino acids.

\subsection{Contents of food-derived peptides in human blood}

Most of the indigestible peptides shown in Figure 3 were detected in human plasma before and after ingestion of the hydrolysates. As shown in Figure 4, three pyroglutamyl peptides, pyroGlu-Pro, py- 


\section{Corn gluten hydrolysate}

$\mathbf{a}$

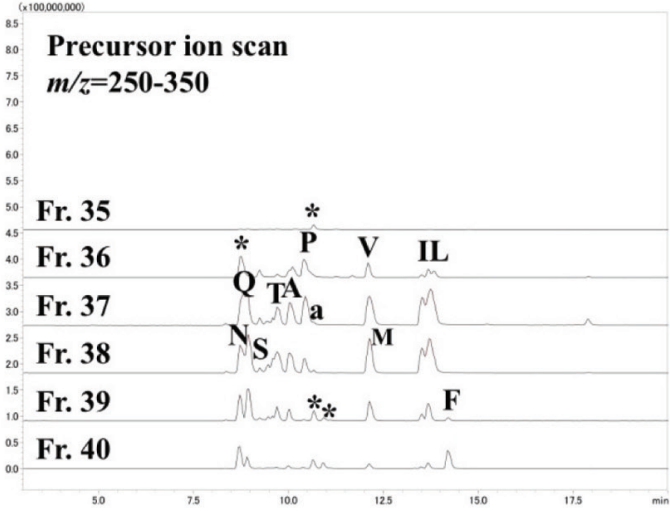

b

\section{Precursor ion scan \\ $m / z=350-450$}

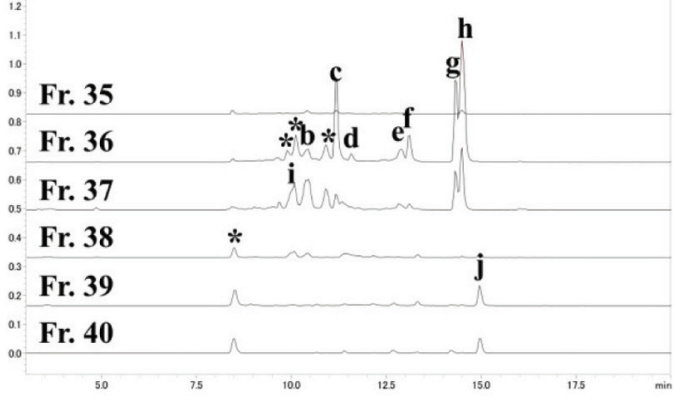

C

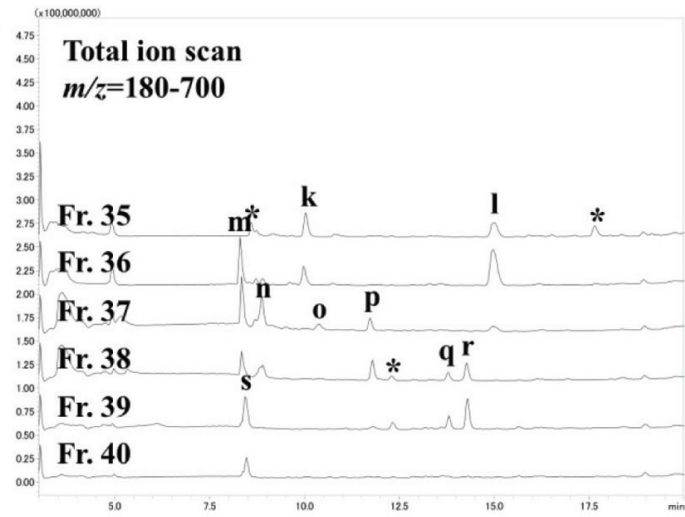

\section{Wheat gluten hydrolysate}
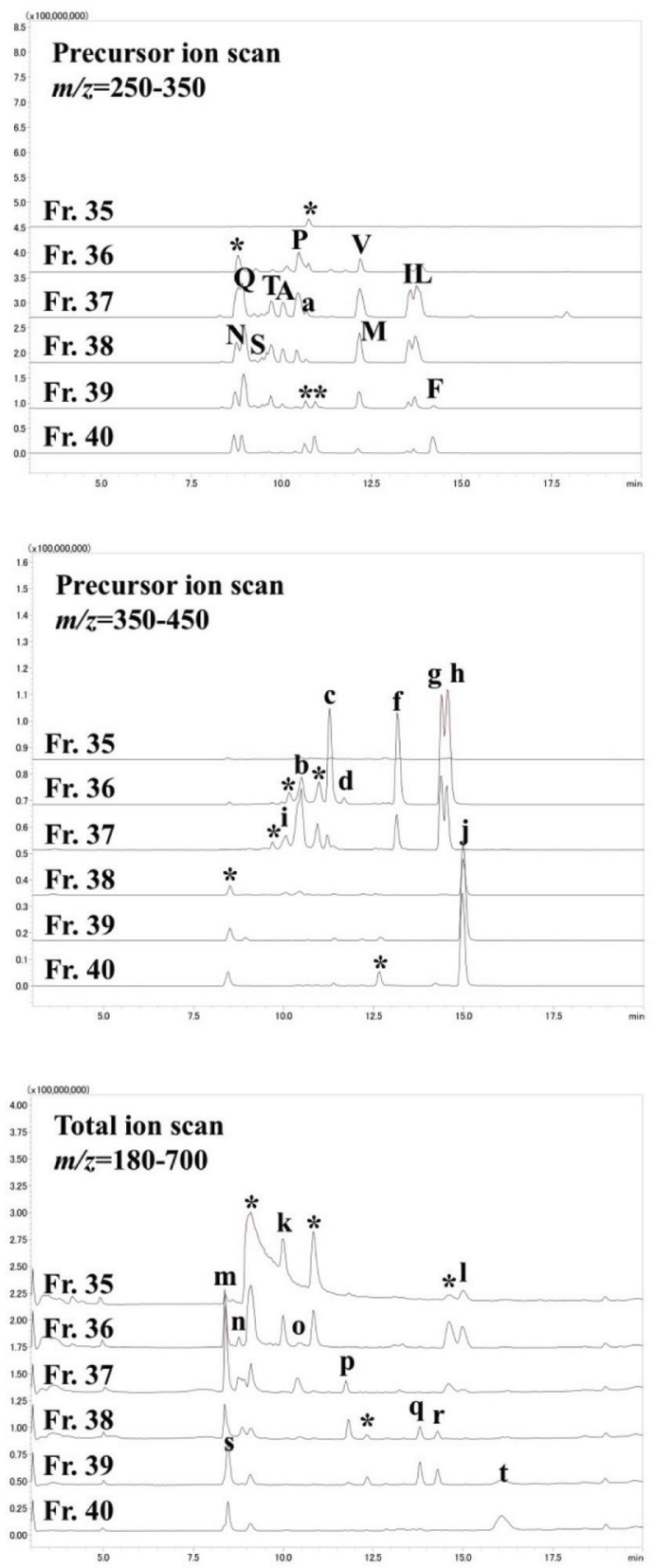

Figure 2. Mass spectrometry chromatograms of AccQ-derivatives $(a, b)$ and pyroglutamyl peptides (c) in SEC fractions 35-40. Peaks marked with uppercase represent amino acid derivatives; lowercase, AccQ-peptides (a-j) and pyroglutamyl peptides (k-t). Peaks marked with asterisks could not be assigned to peptides with any combination of amino acids.

roGlu-Leu-Pro, and pyroGlu-Gln-Pro, were significantly increased after ingestion of corn and wheat gluten hydrolysates. Maximum levels of these peptides were approximately 10-100 nM. Unexpectedly, only the dipeptides with $\mathrm{N}$-terminal prolyl residues (ProAla, Pro-Gly, and Pro-Gln) significantly increased to $20-50 \mathrm{nM}$ after ingestion, while those of peptides in the hydrolysates were much lower than those with C-terminal prolyl residues (Figure 3), which did not increase significantly. The di- and tripeptides ap- proached maximum levels 1 and $4 \mathrm{~h}$ after ingestion, respectively.

\section{Discussion}

Resolution of short-chain peptides, especially hydrophilic peptides, via RP-HPLC is generally inadequate owing to poor retention in the column. To overcome this issue, pre-column labeling 
Table 1. Estimated sequences of peptides in size-exclusion chromatographic fractions of exopeptidase digests of corn (C) and wheat (W) gluten hydrolysates

\begin{tabular}{|c|c|c|c|c|c|}
\hline Origin & SEC Fr. & peak & $\begin{array}{l}\text { estimated pep- } \\
\text { tide sequence }\end{array}$ & $\begin{array}{l}\text { precursor } \\
\text { ions }(\mathrm{m} / \mathrm{z})\end{array}$ & product ions $(\mathrm{m} / \mathrm{z})$ \\
\hline C, W & 37,38 & a & Gly-Pro & 343.3 & 116.1 (y1), $171.0(\mathrm{AccQ}, \mathrm{b} 1), 228$ (b2) \\
\hline C, W & $36-38$ & $\mathrm{~b}$ & Ser-Pro & 373.2 & $116.1(y 1), 171.0\left(\right.$ AccQ, b1), $203\left(\left[y 2-\mathrm{NH}_{3}\right]^{+}\right), 258(\mathrm{~b} 2)$ \\
\hline$C, W$ & $36-38$ & $b$ & Asp-Pro & 401.2 & 70.1 (Asp*), $116(y 1), 171.0(\mathrm{AccQ}, \mathrm{b} 1), 231\left(\left[\mathrm{y} 2-\mathrm{NH}_{3}\right]^{+}\right), 258(\mathrm{a} 2), 286(\mathrm{~b} 2)$ \\
\hline C, W & $36-38$ & b & GIn-Pro & 414.3 & $83.9(\mathrm{Gln} *), 101.1(\mathrm{Gln} *), 116.1$ (y1), 171.0 (AccQ, b1), 271.1 (a2), 298.9 (b2) \\
\hline C, W & $36-37$ & c & Ala-Pro & 357.3 & 116.1 (y1), $171.0(\mathrm{AccQ}, \mathrm{b} 1), 187\left(\left[\mathrm{y} 2-\mathrm{NH}_{3}\right]^{+}\right), 242.1$ (b2) \\
\hline C, W & $36-37$ & $\mathrm{C}$ & Pro-Pro & 383.3 & 70.1 (Pro*), 116.1 (y1), $171.0(\mathrm{AccQ}, \mathrm{b} 1), 213\left(\left[\mathrm{y} 2-\mathrm{NH}_{3}\right]+\right), 268.1$ (b2) \\
\hline C, W & 36 & $\mathrm{~d}$ & Pro-Val & 385.3 & $70.1\left(\right.$ Pro $\left.^{*}\right), 171.0(\mathrm{AccQ}, \mathrm{b} 1), 215\left(\left[\mathrm{y} 2-\mathrm{NH}_{3}\right]^{+}\right)$ \\
\hline C, W & $36-37$ & e & Pro-Ile/Leu & 399.3 & $70.1\left(\right.$ Pro*) ${ }^{*} 171.0(\mathrm{AccQ}, \mathrm{b} 1), 229.1\left(\left[\mathrm{y} 2-\mathrm{NH}_{3}\right]^{+}\right), 240(\mathrm{a} 2), 268.2$ (b2) \\
\hline C, W & $36-37$ & $f$ & Val-Pro & 385.3 & $72.1\left(\mathrm{Val}^{*}\right), 116.1(\mathrm{y} 1), 171.0(\mathrm{AccQ}, \mathrm{b} 1), 215\left(\left[\mathrm{y} 2-\mathrm{NH}_{3}\right]^{+}\right), 242(\mathrm{a} 2), 270.2(\mathrm{~b} 2)$ \\
\hline C, W & $36-37$ & g & Ile-Pro & 399.3 & $86.1\left(\right.$ lle* $\left.^{*}\right), 116.1$ (y1), $171.0(\mathrm{AccQ}, \mathrm{b} 1), 229.1\left(\left[\mathrm{y} 2-\mathrm{NH}_{3}\right]^{+}\right), 256.1(\mathrm{a} 2), 284.1$ (b2) \\
\hline C, W & $36-37$ & $\mathrm{~h}$ & Leu-Pro & 399.3 & $86\left(\right.$ Leu* $\left.^{*}\right), 116.1$ (y1), $171.0(\mathrm{AccQ}, \mathrm{b} 1), 229.1\left(\left[\mathrm{y} 2-\mathrm{NH}_{3}\right]^{+}\right), 256.1(\mathrm{a} 2), 284$ (b2) \\
\hline C, W & $37-38$ & i & Asn-Pro & 400.3 & $70.1\left(\mathrm{Asn}^{*}\right), 116(\mathrm{y} 1), 171.0(\mathrm{AccQ}, \mathrm{b} 1), 230\left(\left[\mathrm{y} 2-\mathrm{NH}_{3}\right]^{+}\right), 256.9(\mathrm{a} 2), 285$ (b2) \\
\hline C, W & $38-40$ & j & Phe-Pro & 433.3 & $116(\mathrm{y} 1), 120\left(\mathrm{Phe}^{*}\right), 171.0(\mathrm{AccQ}, \mathrm{b} 1), 263\left(\left[\mathrm{y} 2-\mathrm{NH}_{3}\right]^{+}\right), 290.1(\mathrm{a} 2), 318(\mathrm{~b} 2)$ \\
\hline C, W & $35-36$ & $\mathrm{k}$ & pyroGlu-GIn-Pro & 355.1 & 70.1 (Pro*), 84 (pyroGlu*), 116 (y1), 212 (a2), 240 (b2) \\
\hline C, W & $35-37$ & I & pyroGlu-Leu-Pro & 340.2 & 70.1 (Pro*), 84 (pyroGlu*), 86 (Leu*), 197.1 (a2) \\
\hline C, W & $36-38$ & $\mathrm{~m}$ & pyroGlu-Gln & 258.1 & 84 (pyroGlu*) \\
\hline C, W & $37-38$ & $\mathrm{n}$ & pyroGlu-Ala & 201.1 & $44.1($ Ala*), 84 (pyroGlu*), 89.9 (y1) \\
\hline C, W & 37 & 0 & pyroGlu-Pro & 227 & 70.1 (Pro*), 83.9 (pyroGlu*), 115.9 (y1) \\
\hline C, W & $37-38$ & $\mathrm{p}$ & pyroGlu-Val & 229.1 & 72.1 (Val*), 84 (pyroGlu*), 118.1 (y1) \\
\hline C, W & $38-39$ & q & pyroGlu-lle & 243.1 & $86.0\left(11 e^{*}\right), 84$ (pyroGlu*) \\
\hline$C, W$ & $38-39$ & r & pyroGlu-Leu & 243.1 & $86.0\left(\right.$ Leu* $\left.^{*}\right), 84$ (pyroGlu*), 132.2 (y1) \\
\hline C, W & $39-40$ & $\mathrm{~s}$ & pGlu-Glu & 259 & 84 (pyroGlu*) \\
\hline W & $39-40$ & $\mathrm{t}$ & pyroGlu-Phe-Pro & 374.1 & 70.1 (Pro*), 84 (pyroGlu*), 116 (y1), 120 (Phe*), 231 (a2) \\
\hline
\end{tabular}

*Immonium ion of amino acid. ** Peaks a-j were AccQ derivatives. SEC: size-exclusion chromatography.
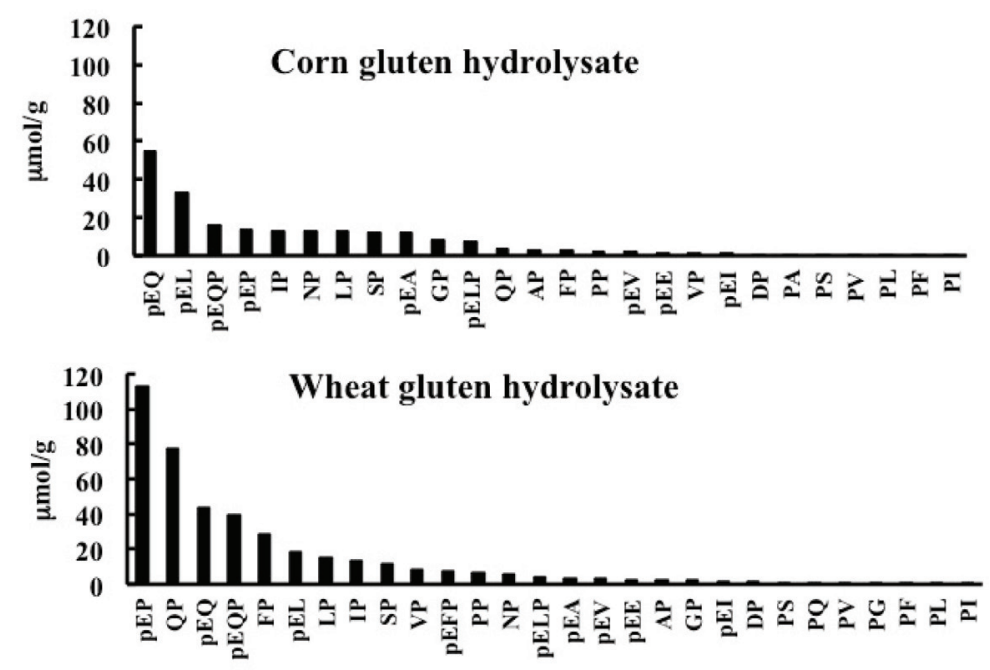

Figure 3. Contents of exopeptidase-resistant peptides from corn and wheat gluten hydrolysates. One-letter abbreviations were used for amino acid residues. pE represents pyroglutamic acid (pyroGlu) residue. 

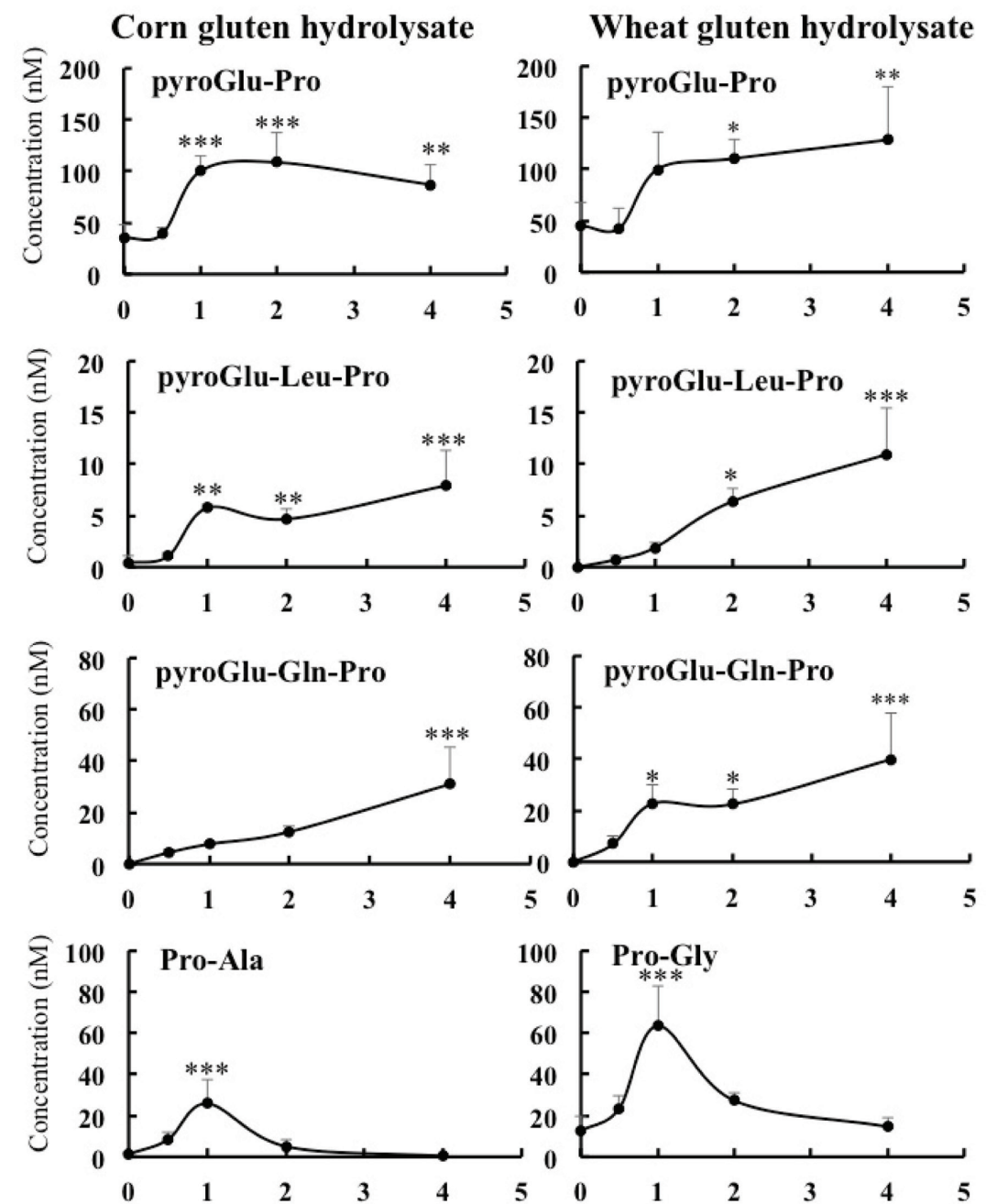

(h)

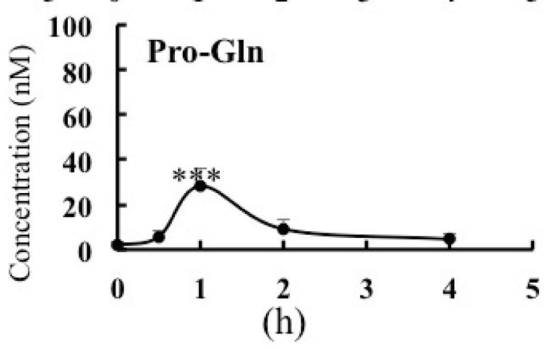

Figure 4. Contents of the exopeptidase-resistant peptides in human blood plasma after ingestion of corn or wheat gluten hydrolysates. Data are shown as the mean \pm standard deviation $(\mathrm{n}=4)$. Asterisks indicate significant differences between values before ingestion $(*: P<0.05, * *: P<0.01, * * *: P<0.001)$

using PITC has previously been used (Aito-Inoue et al., 2006; Shigemura et al., 2011; 2012; 2017). The derivatives, phenyl thiocarbamyl (PTC)-peptides, can be separated via RP-HPLC in higher resolution before the derivatization and directly sequenced via Edman's degradation method. However, ionization efficiency of PTC-peptides in MS analysis was low. In the present study, AccQ was used for derivatization of amino groups, as AccQ-derivatives are ionized with high efficiency and generate product ion of $\mathrm{m} / \mathrm{z}$ $=171.1$ derived from AccQ in MS/MS analysis, which enables specific detection of the components with amino groups by selecting product ion of $m / z=171.1$ via MS/MS in precursor ion scan mode. This method allows for identification of major indigestible peptides in the exopeptidase digests of corn and wheat gluten hydrolysates (Table 1). It may also be applied directly to detect foodderived peptides in human plasma after the ingestion of corn and wheat gluten hydrolysates. However, despite this method, it was difficult to detect the increased peptides after ingestion owing to the presence of numerous amino compounds (data not shown). In the present study, indigestible peptides against carboxypeptidase A in pancreatin and leucine amino peptidase were first identified. It can be assumed that at least part of these indigestible peptides resist exopeptidase digestion in the digestive tract and blood, and are absorbed in the blood. In fact, six indigestible peptides increased in human plasma after ingestion of corn and wheat glu- 
ten hydrolysates. The maximum levels of these peptides in plasma were approximately $10-100 \mathrm{nM}$, which were considerably lower than those of food-derived collagen and elastin peptides (10-50 $\mu$ M) (Iwai et al., 2005, Ohara et al., 2007, Shigemura et al., 2012; 2017). Therefore, it was difficult to directly detect these peptides in blood via LC-MS/MS in precursor ion scan mode. Pre-identification of indigestible peptides against exopeptidases enabled specific detection of the indigestible peptides in blood via LC-MS/MS in MRM mode. The present exopeptidase digestion can degrade approximately $90 \%$ of peptides and provide candidate for the foodderived peptides in the body.

The contents of indigestible dipeptides with C-terminal prolyl residues in the exopeptidase digests of corn and wheat gluten hydrolysates were significantly higher than those with N-terminal prolyl residues (Figure 3). Nevertheless, dipeptides with C-terminal prolyl residues did not increase in plasma after ingestion of corn and wheat gluten hydrolysates. The dipeptides with C-terminal prolyl residue can be degraded by intracellular and plasma prolidase (Cunningham et al., 1997; Lupi et al., 2008), which can explain the inconsistency between in vitro and in vivo results in the present study. For better prediction of the structure of foodderived peptides in the body, other exopeptidases such as prolidase and aminopeptidase $\mathrm{P}$, among others, could be used in addition to leucine aminopeptidase and carboxypeptidase $\mathrm{A}$ in pancreatin.

\section{Conclusion}

The present study shows that 6 prolyl and pyroglutamyl peptides significantly increase in human plasma after ingestion of $9 \mathrm{~g}$ of corn and wheat gluten hydrolysates. Maximum levels of these peptides were approximately $10-100 \mathrm{nM}$. Among them, Pro-Gly attenuated hypertension-induced damage to endothelial cells in arteries of spontaneously hypertensive rats (Takemori et al., 2015). In addition, short-chain pyroglutamyl peptides attenuated hepatitis in rat (Sato et al., 2013) and colitis-induced dysbiosis of mice (Wada et al., 2013; Kiyono et al., 2016) at relatively low doses. The activities of food-derived peptides in plasma might be associated with their beneficial effects on ingestion of corn and wheat gluten hydrolysates, which warrants further confirmation via further in vitro and in vivo studies using these peptides. The present method would be useful to identify food-derived peptides with potential bioactivity in the blood after ingestion of other protein hydrolysates.

\section{References}

Adibi, S.A. (1997). The oligopeptide transporter (Pept-1) in human intestine: biology and function. Gastroenterology. 113: 332-340.

Aito-Inoue, M., Ohtsuki, K., Nakamura, Y., Park, E.Y., Iwai, K., Morimatsu, F., and Sato, K. (2006). Improvement in isolation and identification of food-derived peptides in human plasma based on precolumn derivatization of peptides with phenyl isothiocyanate. J. Agric. Food Chem. 54(15): 5261-5266.

Bidlingmeyer, B.A., Cohen, S.A., and Tarvin, T.L. (1984). Rapid analysis of amino acids using pre-column derivatization. J. Chromatogr. 336: 93-104.

Cunningham, D.F., and O'Connor, B. (1997). Proline specific peptidases. Biochim. Biophys. Acta. 1343: 160-186.

Higaki-Sato, N., Sato, K., Inoue, N., Nawa, Y., Kido, Y., Nakabou, Y., Hashimoto, K., Nakamura, Y., and Ohtsuki, K. (2006). Occurrence of the free and Peptide forms of pyroglutamic acid in plasma from the portal blood of rats that had ingested a wheat gluten hydrolysate con- taining pyroglutamyl peptides. J. Agric. Food Chem. 54: 6984-6988.

Hübl, W., Druml, W., Langer, K., and Lochs, H. (1989). Influence of molecular structure and plasma hydrolysis on the metabolism of glutaminecontaining dipeptides in humans. Metabolism 38: 59-62.

Iwai, K., Hasegawa, T., Taguchi, Y., Morimatsu, F., Sato, K., Nakamura, Y., Higashi, A., Kido, Y., Nakabo, Y., and Ohtsuki, K. (2005). Identification of food-derived collagen peptides in human blood after oral ingestion of gelatin hydrolysates. J. Agric. Food Chem. 53: 6531-6536.

Kiyono, T., Hirooka, K., Yamamoto, Y., Kuniishi, S., Ohtsuka, M., Kimura, S., Park, E.Y., Nakamura, Y., and Sato, K. (2013). Identification of pyroglutamyl peptides in Japanese rice wine (Sake): presence of hepatoprotective pyroGlu-Leu. J. Agric. Food Chem. 61: 11660-11667.

Kiyono, T., Wada, S., Ohta, R., Wada, E., Takagi, T., Naito, Y., Yoshikawa, T., and Sato, K. (2016). Identification of pyroglutamyl peptides with anticolitic activity in Japanese rice wine, sake, by oral administration in a mouse model. J. Funct. Foods 27: 612-621.

Koikawa, N., Nakamura, A., Ngaoka, I., Aoki, K., Sawaki, K., and Suzuki, Y. (2009). Delayed-onset muscle injury and its modification by wheat gluten hydrolysate. Nutrition 25: 493-498.

Lupi, A., Tenni, R., Rossi, A., Cetta, G., and Forlino, A. (2008). Human prolidase and prolidase deficiency: an overview on the characterization of the enzyme involved in proline recycling and on the effects of its mutations. Amino Acids 35: 739-752.

Malaguti, M., Dinelli, G., Leoncini, E., Bregola, V., Bosi, S., Cicero, A.F., and Hrelia, S. (2014). Bioactive peptides in cereals and legumes: agronomical, biochemical and clinical aspects. Int. J. Mol. Sci. 15: 2112021135.

Miner-Williams, W.M., Stevens, B.R., and Moughan, P.J. (2014). Are intact peptides absorbed from the healthy gut in the adult human? Nutr. Res. Rev. 27: 308-329.

Möller, N.P., Scholz-Ahrens, K.E., Roos, N., and Schrezenmeir, J. (2008). Bioactive peptides and proteins from foods: indication for health effects. Eur. J. Nutr. 47: 171-182.

Nakatani, S., Mano, H., Sampei, C., Shimizu, J., and Wada, M. (2009). Chondroprotective effect of the bioactive peptide prolyl-hydroxyproline in mouse articular cartilage in vitro and in vivo. Osteoarthritis Cartilage 17: 1620-1627.

Ohara, H., Matsumoto, H., Ito, K., Iwai, K., and Sato, K. (2007). Comparison of quantity and structures of hydroxyproline-containing peptides in human blood after oral ingestion of gelatin hydrolysates from different sources. J. Agric. Food Chem. 55: 1532-1535.

Ohara, H., Ichikawa, S., Matsumoto, H., Akiyama, M., Fujimoto, N., Kobayashi, T., and Tajima, S. (2010). Collagen-derived dipeptide, prolinehydroxyproline, stimulates cell proliferation and hyaluronic acid synthesis in cultured human dermal fibroblasts. J. Dermatol. 37: 330-338

Proksch, E., Segger, D., Degwert, J., Schunck, M., Zagued, V., and Oesser, S. (2014a). Oral Supplementation of specific collagen peptides has beneficial effects on human skin physiology: A double-blind, placebo-controlled study. Skin Pharmacol. Physiol. 27: 47-55.

Proksch, E., Schunck, M., Zague, V., Segger, D., Degwert, J., and Oesser, S. (2014b). Oral intake of specific bioactive collagen peptides reduces skin wrinkles and increases dermal matrix synthesis. Skin Pharmacol. Physiol. 27: 113-119.

Satake, M., Enjoh, M., Nakamura, Y., Takano, T., Kawamura, Y., Arai, S., and Shimizu, M. (2002). Transepithelial transport of the bioactive tripeptide, Val-Pro-Pro, in human intestinal Caco-2 cell monolayers. Biosci. Biotechnol. Biochem. 66: 378-384.

Sato, K., Tsukamasa, Y., Imai, C., Ohtsuki, K., Shimizu, Y., and Kawabata, M. (1992). Improved method for identification and determination of $\varepsilon$-( $\gamma$-glutamyl)-lysine cross-link in protein using proteolytic digestion and derivatization with phenyl isothiocyanate followed by highperformance liquid chromatography separation. J. Agric. Food Chem. 40: 806-810.

Sato, K., Egashira, Y., Ono, S., Mochizuki, S., Shimmura, Y., Suzuki, Y., Nagata, M., Hashimoto, K., Kiyono, T., Park, E.Y., Nakamura, Y., Itabashi, M., Sakata, Y., Furuta, S., and Sanada, H. (2013). Identification of a hepatoprotective peptide in wheat gluten hydrolysate against Dgalactosamine-induced acute hepatitis in rats. J. Agric. Food Chem. 61: 6304-6310.

Shigemura, Y., Iwai, K., Morimatsu, F., Iwamoto, T., Mori, T., Oda, C., Taira, 
T., Park, E.Y., Nakamura, Y., and Sato, K. (2009). Effect of Prolyl-hydroxyproline (Pro-Hyp), a food-derived collagen peptide in human blood, on growth of fibroblasts from mouse skin. J. Agric. Food Chem. 57: 444-449.

Shigemura, Y., Akaba, S., Kawashima, E., Park, E.Y., Nakamura, Y., and Sato, K. (2011). Identification of a novel food-derived collagen peptide, hydroxyprolyl-glycine, in human peripheral blood by pre-column derivatisation with phenyl isothiocyanate. Food Chem. 129: 1019-1024.

Shigemura, Y., Nakaba, M., Shiratsuchi, E., Suyama, M., Yamada, M., Kiyono, T., Fukamizu, K., Park, E.Y., Nakamura, Y., and Sato, K. (2012). Identification of food-derived elastin peptide, prolyl-glycine (ProGly), in human blood after ingestion of elastin hydrolysate. J. Agric. Food Chem. 60: 5128-5133.

Shigemura, Y., Suzuki, A., Kurokawa, M., Sato, Y., and Sato, K. (2017). Changes in composition and content of food-derived peptide in human blood after daily ingestion of collagen hydrolysate for 4 weeks. J. Sci. Food Agric. 98: 1944-1950.

Shimizu, M., Tsunogai, M., and Arai, S. (1997). Transepithelial transport of oligopeptides in the human intestinal cell, Caco-2. Peptides 18 681-687.
Sugihara, F., Inoue, N., Koizumi, S., and Sriaam, V.T. (2015). Collagen hydrolysate enhanced pressure ulcer healing in a randamized doubleblind placebo-controlled clinical study. Jpn. Pharmacol. Ther. 43: 1323-1328.

Takemori, K., Yamamoto, E., Ito, H., and Kometani, T. (2015). Prophylactic effects of elastin peptide derived from the bulbus arteriosus of fish on vascular dysfunction in spontaneously hypertensive rats. Life Sci. 120: 48-53.

Wada, S., Sato, K., Ohta, R., Wada, E., Bou, Y., Fujiwara, M., Kiyono, T., Park, E.Y., Aoi, W., Takagi, T., Naito, Y., and Yoshikawa, T. (2013). Ingestion of low dose pyroglutamyl leucine improves dextran sulfate sodiuminduced colitis and intestinal microbiota in mice. J. Agric. Food Chem. 61: 8807-8813.

Wu, Y., Pan, X., Zhang, S., Wang, W., Cai, M., Li, Y., Yang, F., and Guo, H. (2014). Protective effect of corn peptides against alcoholic liver injury in men with chronic alcohol consumption: a randomized doubleblind placebo-controlled study. Lipids Health Dis. 13: 192.

Zdzieblik, D., Oesser, S., Gollhofer, A., and König, D. (2017). Improvement of activity-related knee joint discomfort following supplementation of specific collagen peptides. Appl. Physiol. Nutr. Metab. 42: 588-595. 